\title{
Editorial
}

\section{Aquatic Environmental Health and Toxicology}

\author{
Zhi-Hua Li, ${ }^{1,2}$ Kaiyu He, ${ }^{3}$ Chunsheng Liu, ${ }^{4}$ Ping Li, ${ }^{1,2}$ and Vladimir Zlabek ${ }^{2}$ \\ ${ }^{1}$ Yangtze River Fisheries Research Institute, Chinese Academy of Fishery Sciences, No. 8, 1st Wudayuan Road, \\ East Lake Hi-Tech Development Zone, Wuhan, Hubei 430223, China \\ ${ }^{2}$ Faculty of Fisheries and Protection of Waters, University of South Bohemia in České Budějovice, Zátiší 728/II, \\ 38925 Vodňany, Czech Republic \\ ${ }^{3}$ Biomedical Sciences Research Building (BSRB), University of Michigan, 109 Zina Pitcher Place, Ann Arbor, MI 48109-2200, USA \\ ${ }^{4}$ College of Fisheries, Huazhong Agricultural University, No. 1 Shizishan Street, Hongshan District, Wuhan, Hubei 430070, China
}

Correspondence should be addressed to Zhi-Hua Li; zhihuali06@yahoo.com

Received 5 December 2016; Accepted 7 December 2016

Copyright (C) 2016 Zhi-Hua Li et al. This is an open access article distributed under the Creative Commons Attribution License, which permits unrestricted use, distribution, and reproduction in any medium, provided the original work is properly cited.

Nowadays, thousands of pollutants enter into the water environment and exert various kinds of stress on aquatic organisms, which can in many cases result in negative changes in water quality. Water-inhabiting organisms constitute one of the essential components of the ecosystem. Recently, awareness of the adverse effects of chemical contamination is growing as investigations into these pollutants increase and analytical detection techniques improve. The aquatic environment, as an important component of the biosphere, has been termed "the ultimate sink" for natural and man-made chemicals. Given the finite supply of water available, the continued chemical contamination of the aquatic environment may pose a significant environmental health hazard. Laboratories from Turkey, Brazil, India, and China submitted 19 papers. Altogether, 9 original papers were accepted after the reviewing process.

For the part bookmarks and mechanisms of aquatic toxicology, six papers have been accepted. Toxicity tests were conducted with sea cucumber (Apostichopus japonicus) exposed to heavy metals by L. Li et al., who found that, under acute or chronic heavy metal stress, the sea cucumber has many physiological adaption mechanisms including decrease or increase of oxygen consumption rate and adjusted activity of metabolic enzymes. L. Geng et al. evaluated the individual and combined effects of salinity and alkalinity on gill $\mathrm{Na}^{+} / \mathrm{K}^{+}$-ATPase enzyme activity, plasma ion concentration, and osmotic pressure in Luciobarbus capito. The toxic effects of carbon quantum dots (CDs) on rare minnow (Gobiocypris rarus) embryos at different developmental stages were investigated by Y.-Y. Xiao et al., who found that the mechanism of CDs exposure might result from the pressure of induced oxidative stress coordinate with the dysregulated development related gene expression mediated. L. Luo et al. demonstrated that adding strain SP1 to aquaculture wastewater could effectively reduce the COD, TAN, and SS and accelerate biofloc formation.

For the part environmental factors and aquatic environmental health, three papers have been accepted. J. Li et al. studied the impacts of dam construction on fish, which provided basic knowledge of spatiotemporal distribution and assemblages of fishes in the extended reaches downstream of Gezhouba Dam. X. Bi et al. found that heavy metals with different stimulatory effects on different stages of the formation of Microcystis colonies might be one factor that contributes to the occurrence of $M$. aeruginosa blooms in natural conditions, through investigating the sequestration and distribution characteristics of Cd(II) by Microcystis aeruginosa and its role in Microcystis colony formation. To provide more reasonable references for remedying underground water, Y. Cheng et al. carried out a study that was conducted to achieve a better understanding of the migration and distribution of benzene, toluene, ethyl benzene, and xylene (BTEX). And they concluded that alleviating BTEX pollution in underground water by increasing the concentrations of electric acceptors, such as nitrate, and by enhancing microbial activities is an effective and noteworthy method.

The papers of this special issue comprise critical and new areas of research and recent advances on challenging issues in different fields of aquatic environmental health and toxicology, which tried to stimulate the continuing efforts to 
understand the adverse effects and toxicological mechanisms of chemical contaminants in aquatic systems. We hope that the special issue will attract more interest from many people, including scientists, researchers, and related governments concerned about aquatic environmental health.

Zhi-Hua Li

Kaiyu He

Chunsheng Liu

Ping Li

Vladimir Zlabek 

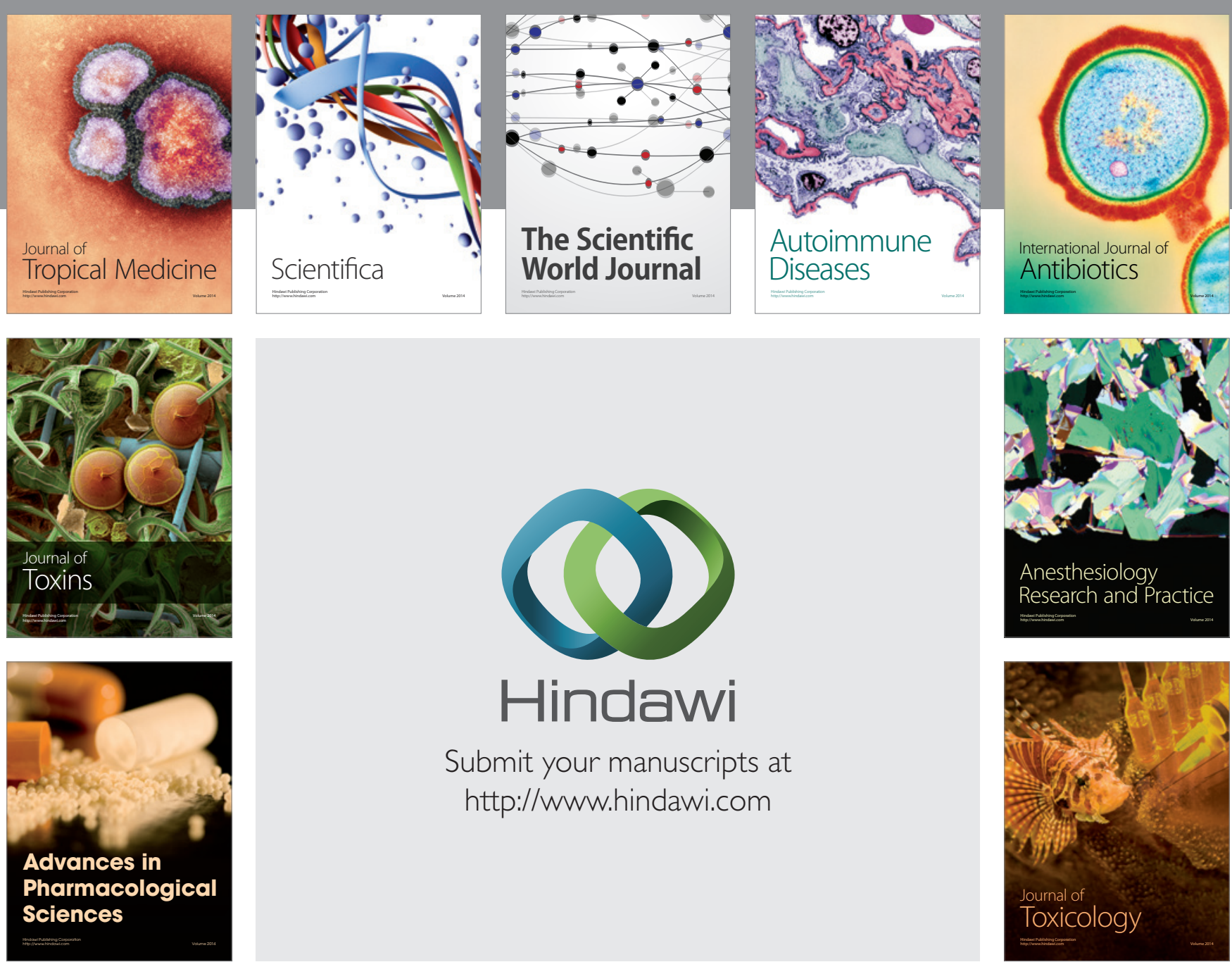

\section{Hindawi}

Submit your manuscripts at

http://www.hindawi.com
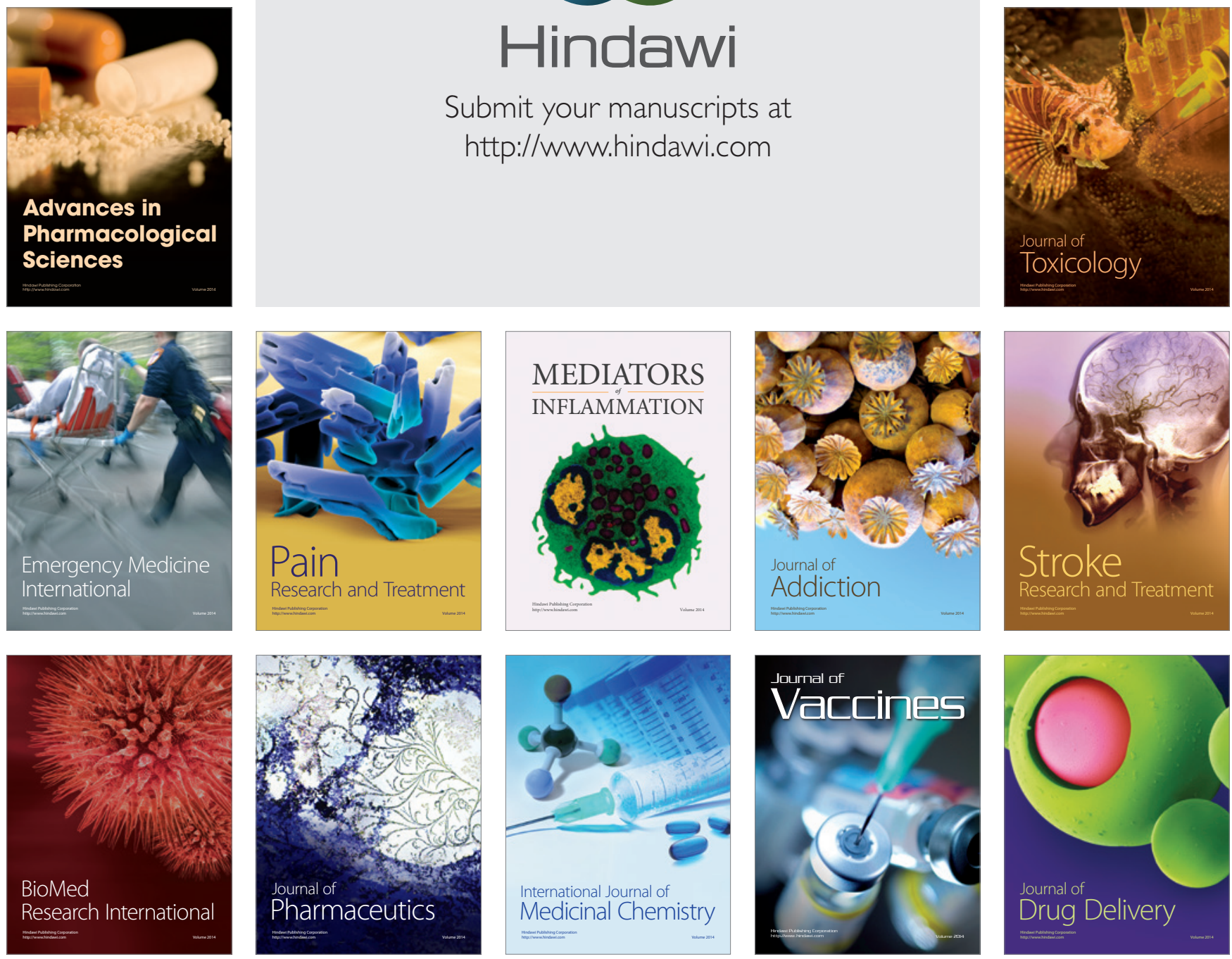